\title{
Sofosbuvir-based therapy for patients with chronic hepatitis C: Early experience of its efficacy and safety in Korea
}

\author{
Yuri Cho, Eun Ju Cho, Jeong-Hoon Lee, Su Jong Yu, Jung-Hwan Yoon, and Yoon Jun Kim \\ Department of Internal Medicine and Liver Research Institute, Seoul National University College of Medicine, Seoul, Korea
}

Background/Aims: The previous standard treatment for chronic hepatitis C (CHC) patients, comprising a combination of pegylated interferon (IFN) and ribavirin, was associated with suboptimal efficacy and severe adverse reactions. A new era of direct-acting antivirals is now dawning in Korea. Early experience of applying sofosbuvir-based therapy to CHC patients in Korea is reported herein.

Methods: Data on efficacy and safety were collected for $\mathrm{CHC}$ patients treated with a combination of sofosbuvir plus ribavirin or sofosbuvir/ledipasvir with or without ribavirin.

Results: This retrospective study included 25 consecutive patients who received sofosbuvir-based therapy (19 with genotype $1 \mathrm{~b}$ and 6 with genotype 2) at Seoul National University Hospital from May 2014 to April 2015. A virologic response was achieved at week 4 by $85.7 \%$ and $80 \%$ of the patients with genotypes $1 \mathrm{~b}$ and 2 , respectively. The HCVRNA level decreased more slowly in IFN-experienced than in treatment-naïve patients with genotype $1 \mathrm{~b}$. However, the sustained virologic response at week 12 (SVR12) rate did not differ among these patients, and was as high as 100\%. The presence of cirrhosis significantly increased the risk of a virologic response failure at week $4(\mathrm{OR}, 11.0 ; P=0.011)$ among patients with HCV genotype $1 \mathrm{~b}$. Only five patients (20\%) experienced minor adverse events, including grade 1 fatigue and headache. The hemoglobin level decreased slightly after sofosbuvir-based therapy, but there was no case of premature discontinuation of this therapy.

Conclusions: In a real clinical practice, sofosbuvir-based therapy for CHC patients in Korea achieved optimal antiviral efficacy with insignificant adverse events. Long-term follow-up data are warranted to ensure the sustained antiviral efficacy and long-term safety of sofosbuvir-based IFN-free therapy. (Clin Mol Hepatol 2015;21:358-364)

Keywords: Chronic hepatitis C; Direct-acting antiviral; Korea

\section{INTRODUCTION}

Previous standard treatment option for chronic hepatitis C (CHC) patients was a combination of pegylated interferon (IFN) and ribavirin. ${ }^{1-3}$ However, this combination treatment shows suboptimal efficacy in viral response with severe adverse reactions. ${ }^{4,5}$ Currently, new era of $\mathrm{CHC}$ treatment has been coming. Now, directacting antivirals (DAAs) are available in Korea with well-established efficacy for CHC patients. First-wave protease inhibitors including telaprevir or boceprevir were introduced in 2014. How-

\section{Abbreviations:}

ALT, alanine aminotransferase; CHC, chronic hepatitis $\mathrm{C}_{;} \mathrm{Cl}$, confidence interval; DAA, direct-acting antiviral; $\mathrm{HCV}$, hepatitis $\mathrm{C}$ virus; IFN, interferon; NS, nonstructural protein; OR, odds ratio; $\mathrm{PT}$, prothrombin time; RNA, ribonucleic acid; SD, standard deviation; SVR, sustained virologic response; TE, transient elastography; WBC, white blood cell

\section{Corresponding author : Yoon Jun Kim}

Department of Internal Medicine and Liver Research Institute, Seoul National University College of Medicine, 101 Daehak-ro, Jongno-gu, Seoul 03080, Korea

Tel: +82-2-2072-3081, Fax: +82-2-743-6701

E-mail:yoonjun@snu.ac.kr 
ever, many other second-generation DAAs targeting nonstructural protein (NS) 3 protease, NS5A and NS5B polymerase are being developed.

Many studies from Western countries reported that several DAAs exhibit potent antiviral activity with high sustained virologic response (SVR) rate, even in difficult-to-treat patients including old patients, patients with a liver cirrhosis, and those who failed to previous pegylated IFN plus ribavirin treatment. Use of pegylated IFN-free regimen with DAAs has shown very high SVR rates, up to nearly $100 \%$, with insignificant side effects. In Western countries, interferon-free regimen is the new standard treatment for CHC patients. Now, second-generation DAAs including sofosbuvir or sofosbuvir/ledipasvir are available in Korea through the Korea Orphan Drug Center.

Sofosbuvir is an oral nucleotide analogue inhibitor targeting hepatitis C virus (HCV)-specific NS5B polymerase. ${ }^{6}$ Sofosbuvirbased IFN-free therapies for patients with HCV genotype 1 infection include sofosbuvir/ledipasvir with/without ribavirin for 8-12 weeks. ${ }^{7,8}$ Ledipasvir is a new HCV-NS5A inhibitor with antiviral activity against HCV genotype $1 .{ }^{9} \mathrm{~A}$ combination of sofosbuvir plus ribavirin without ledipasvir had been used as one of the alternative treatment options against HCV genotype 1, 10,11 although which is no more recommended in current guidelines. ${ }^{7.8}$ For the treatment against HCV genotype 2, sofosbuvir plus ribavirin for 12 weeks (or 16 weeks for cirrhosis) is recommended in both American Association for the Study of Liver Diseases (AASLD) ${ }^{7}$ and European Association for the Study of the Liver (EASL) guidelines. ${ }^{12}$

For the patients in Western countries, sofosbuvir-based therapy has showed high rate of SVR in CHC patients with both HCV genotype 1 and 2., ${ }^{13,14}$ However, the real-life clinical outcomes of these new DAAs in Korea, where ethnic difference exists, are not yet available. Therefore, in this study, we report the real-life experience of sofosbuvir-based IFN-free therapies in Korea including its efficacy and safety.

\section{MATERIALS AND METHODS}

\section{Study subjects}

All patients who received sofosbuvir-based therapy (sofosbuvir $400 \mathrm{mg}$ or sofosbuvir $400 \mathrm{mg} /$ ledipasvir $90 \mathrm{mg}$ plus ribavirin per day) in Seoul National University Hospital were included in this study. All of the patients were older than 18 years old. Sofosbuvir was administered at a dose of $400 \mathrm{mg}$ per day. A combination tablet of sofosbuvir/ledipasvir was administered at a fixed dose of $400 \mathrm{mg}$ and $90 \mathrm{mg}$ per day, respectively. Ribavirin was administered twice per day with doses according to patient's body weight $(1,000 \mathrm{mg}$ daily for the patients with $<75 \mathrm{~kg} ; 1,200 \mathrm{mg}$ daily for the patient with $\geq 75 \mathrm{~kg}$ ).

HCV RNA levels and genotype were determined with the Abbott Real-Time PCR HCV assay (Abbott Molecular Inc., IL, USA), with a lower limit of quantification of $12 \mathrm{IU} / \mathrm{mL}$. Virologic response was defined as undectetable HCV RNA. We defined virologic breakthrough as the presence, during treatment, of serum HCV RNA concentrations $\geq 12 \mathrm{IU} / \mathrm{mL}$ after previous documentation of on-treatment HCV RNA $<12 \mathrm{IU} / \mathrm{mL}^{7}$. Virologic relapse was defined as the presence of serum HCV RNA $\geq 12 \mathrm{IU} / \mathrm{mL}$ at any time during the post-treatment follow-up period after documentation of serum HCV RNA $<12 \mathrm{IU} / \mathrm{mL}$ at the end of treatment. ${ }^{7}$

Safety was assessed by reviewing adverse events and clinical laboratory tests including hematological assessments, and physical examinations.

\section{Follow-up}

Physical examinations, assessment of vital signs, laboratory tests, and serum HCV RNA levels were assessed during the treatment. The virologic responses were obtained at baseline, 4 weeks, 12 weeks, right after the completion of treatment, and 4 and 12 weeks after the completion of sofosbuvir-based therapy, retrospectively. Serum alanine aminotransferase (ALT), albumin, total bilirubin concentration, and prothrombin time (PT) were measured using standard laboratory procedures. Virologic response at 12 weeks after the end of treatment was defined as SVR 12. ${ }^{7}$ The presence of $L C$ was evaluated by noninvasive liver fibrosis test including transient elastography (TE) or by the clinical manifestations including thrombocytopenia, splenomegaly, esophageal/gastric varices, or ascites. Patient with TE score of more than $12.5 \mathrm{kPa}$ (on a scale of 1.5 to $75.0 \mathrm{kPa}$ ) was regarded as cirrhotic patient. ${ }^{15}$ The upper limit of normal ALT was defined as $40 \mathrm{IU} / \mathrm{L}$. Adherence to drug therapy was assessed by counting the number of remaining pills during each visit. Non-compliant patients were excluded from the study.

The study was approved by the Institutional Review Board of Seoul National University Hospital.

\section{Statistical analysis}

The efficacy parameter included serum HCV-RNA on a logarith- 
mic scale. To evaluate the prognostic factors for virologic response at week 4, so called rapid virologic response which is a significant surrogate marker for SVR in the patients treated with DAAs, we performed logistic regression analyses. ${ }^{7,10}$ Statistical analysis was performed with SPSS version 22.0 (SPSS Institute Inc.; Chicago, IL, USA). Statistical hypotheses with $P<0.05$ were considered statistically significant.

\section{RESULTS}

\section{Baseline characteristics}

This retrospective study included 25 consecutive CHC patients who were treated with sofosbuvir-based therapy (13: sofosbuvir plus RBV; 12: sofosbuvir/ledipasvir plus RBV) in Seoul National University Hospital from May 2014 to April 2015. Nineteen patients were with genotype $1 \mathrm{~b}$ and six were with genotype 2 (Table 1). The median HCV RNA was $6.1 \log _{10} \mathrm{IU} / \mathrm{mL}$ (range, 4.2-7.1 $\log _{10} \mathrm{IU} /$ $\mathrm{mL}$ ). Eight (32\%) patients were with liver cirrhosis. Among eight patients, three patients were diagnosed as liver cirrhosis with TE. Patients with HCV genotype $1 b(n=19)$ were treated with sofos- buvir/ledipasvir + ribavirin for at least 12 weeks $(n=12)$ or sofosbuvir + ribavirin for 24 weeks $(n=7)$. Patients with HCV genotype 2 were treated with sofosbuvir + ribavirin for at least 12 weeks $(\mathrm{n}=6)$. One IFN-experienced cirrhotic patient with HCV genotype 2 who had been treated with sofosbuvir + ribavirin for 26.1 weeks was included in this study. There was no patient who did not complete the treatment course nor who were not compliant to therapy. Treatment regimen was decided according to the availability of drug at the time of starting therapy and the costs.

\section{Virologic responses in genotype $1 \mathrm{~b}$}

The median duration of sofosbuvir-based therapy was 14.9 weeks (range, 12.6-25.7 weeks). During treatment, 85.7\% (12/14) of patients achieved virologic response at week 4 and $92.9 \%$ (13/14) of patients achieved virologic response at week 12. After treatment, 100\% of patients achieved SVR 12.

Among 19 patients with HCV genotype 1b, 12 patients completed a combination therapy of sofosbuvir/ledipasvir + ribavirin for at least 12 weeks. Among those 12 patients, only one patient was with detectable HCV RNA at week 4, as high as $40 \mathrm{IU} / \mathrm{mL}$. After week 12, all patients achieved virologic response with unde-

Table 1. Baseline characteristics

\begin{tabular}{|c|c|c|c|}
\hline Variable & $\begin{array}{l}\text { Genotype } 1 \mathrm{~b} \\
\quad(n=19)\end{array}$ & $\begin{array}{c}\text { Genotype } 2 \\
(n=6)\end{array}$ & $\begin{array}{c}\text { Total } \\
(n=25)\end{array}$ \\
\hline Age, year (range) & $65(23-80)$ & $52(48-66)$ & $57(23-80)$ \\
\hline Male sex (\%) & $12(63.2 \%)$ & $3(50 \%)$ & $15(60 \%)$ \\
\hline BMI $\left(\mathrm{kg} / \mathrm{m}^{2}\right)$ & $21.1(18.6-31.6)$ & $23.4(19-26.6)$ & $21.8(18.6-31.6)$ \\
\hline HCV RNA $\left(\log _{10} I U / m L\right)$ & $6.1(4.2-7.1)$ & $6.2(4.9-6.5)$ & $6.1(4.2-7.1)$ \\
\hline Serum ALT (IU/L) & $35(14-235)$ & $48(15-112)$ & $37(14-235)$ \\
\hline Normal ALT (<40 IU/L) & $8(42.1 \%)$ & $2(33.3 \%)$ & $10(40 \%)$ \\
\hline WBC $\left(\times 10^{3} / \mu \mathrm{L}\right)$ & $4.8(1.4-8.0)$ & $4.9(3.6-8.4)$ & $4.8(1.4-8.4)$ \\
\hline Hemoglobin (g/dL) & $14.1(6.9-17.1)$ & $14.9(11.3-16.5)$ & $13.7(6.9-17.1)$ \\
\hline Serum total bilirubin (mg/dL) & $0.7(0.2-1.4)$ & $3.8(0.4-4.7)$ & $0.8(0.2-4.7)$ \\
\hline Serum albumin (g/dL) & $4.3(3.3-4.7)$ & $3.9(2.7-4.2)$ & $4(2.7-4.7)$ \\
\hline Prothrombin time-INR & $1(0.9-1.1)$ & $1.2(1-1.5)$ & $1(0.9-1.5)$ \\
\hline Liver cirrhosis (\%) & $5(26.3 \%)$ & $3(50 \%)$ & $8(32 \%)$ \\
\hline \multicolumn{4}{|l|}{ Treatment regimen } \\
\hline Sofosbuvir + ribavirin & 7 & 6 & $13(52 \%)$ \\
\hline Sofosbuvir/ledipasvir + ribavirin & 12 & 0 & $12(48 \%)$ \\
\hline Duration of treatment, weeks & $14.9(12.6-25.7)$ & $15.4(12.9-26.1)$ & $15.4(12.6-26.1)$ \\
\hline History of previous IFN-based treatments & $5(26.3 \%)$ & $1(16.7 \%)$ & $6(24 \%)$ \\
\hline
\end{tabular}

NOTE. Data are expressed as $n$ (\%) or median with range.

BMI, body mass index; HCV, hepatitis C virus; ALT, alanine aminotransferase; WBC, white blood cell; INR, international normalized ratio; IFN, interferon. 
Table 2. Virologic responses to sofosbuvir-based therapy

\begin{tabular}{|c|c|c|c|}
\hline Response & Treatment-naïve & Prior IFN-treatment & Total \\
\hline \multicolumn{4}{|c|}{ HCV RNA <12 IU/mL, no./total no. (\%) } \\
\hline Genotype 1b & $n=14$ & $n=5$ & $n=19$ \\
\hline \multicolumn{4}{|c|}{ During treatment } \\
\hline Week 4 & $12 / 14(85.7 \%)$ & $3 / 5(60 \%)$ & 15/19 (78.9\%) \\
\hline Week 12 & 13/14 (92.9\%) & $4 / 5(80 \%)$ & $17 / 19(89.5 \%)$ \\
\hline Week 24 & $4 / 4(100 \%)$ & $3 / 3(100 \%)$ & $7 / 7(100 \%)$ \\
\hline \multicolumn{4}{|c|}{ After treatment } \\
\hline Week 4 & $14 / 14(100 \%)$ & $5 / 5(100 \%)$ & $19 / 19(100 \%)$ \\
\hline Week 12 & $7 / 7(100 \%)$ & $3 / 3(100 \%)$ & 10/10 (100\%) \\
\hline Genotype 2 & $n=5$ & $n=1$ & $n=6$ \\
\hline \multicolumn{4}{|c|}{ During treatment } \\
\hline Week 4 & $5 / 5(100 \%)$ & $0 / 1(0 \%)$ & $5 / 6(83.3 \%)$ \\
\hline Week 12 & $5 / 5(100 \%)$ & 1/1 (100\%) & $6 / 6(100 \%)$ \\
\hline \multicolumn{4}{|c|}{ After treatment } \\
\hline Week 4 & $5 / 5(100 \%)$ & 1/1 (100\%) & $6 / 6(100 \%)$ \\
\hline Week 12 & $3 / 3(100 \%)$ & $1 / 1(100 \%)$ & $4 / 4(100 \%)$ \\
\hline
\end{tabular}

IFN, interferon; $\mathrm{HCV}$, hepatitis C virus; no., number.

Table 3. Treatment regimen and duration of sofosbuvir-based therapy and sustained virologic response at week 12 (SVR12)

\begin{tabular}{|c|c|c|c|}
\hline & Treatment regimen & Duration & SVR12 \\
\hline \multicolumn{4}{|l|}{ Genotype $1 b(n=19)$} \\
\hline Treatment-naïve patients with LC ( $n=2)$ & Sofosbuvir/ledipasvir + ribavirin $(n=2)$ & 17.0-16.9 weeks & $100 \%(1 / 1)$ \\
\hline IFN-experienced patients with LC $(n=5)$ & Sofosbuvir/ledipasvir + ribavirin $(\mathrm{n}=5)$ & 16.9-25.7 weeks & $100 \%(3 / 3)$ \\
\hline \multirow[t]{2}{*}{ Treatment-naïve patients without LC $(n=12)$} & Sofosbuvir/ledipasvir + ribavirin $(n=5)$ & 12.6-14.9weeks & $100 \%(4 / 4)$ \\
\hline & Sofosbuvir+ ribavirin $(n=7)$ & 16.9-23.6 weeks & $100 \%(2 / 2)$ \\
\hline \multicolumn{4}{|l|}{ Genotype $2(n=6)$} \\
\hline Treatment-naïve patients with $\mathrm{LC}(\mathrm{n}=2)$ & Sofosbuvir+ ribavirin & 15.7-17.1 weeks & $100 \%(1 / 1)$ \\
\hline IFN-experienced patients with $\mathrm{LC}(\mathrm{n}=1)$ & Sofosbuvir+ ribavirin & 26.1 weeks & $100 \%(1 / 1)$ \\
\hline Treatment-naïve patients without LC $(n=3)$ & Sofosbuvir+ ribavirin & 12.9-15.4 weeks & $100 \%(2 / 2)$ \\
\hline
\end{tabular}

LC, liver cirrhosis; IFN, interferon; SVR, sustained virologic response.

tectable HCV RNA.

Seven patients with HCV-genotype $1 \mathrm{~b}$ completed a combination therapy of sofosbuvir + ribavirin for at least 24 weeks. Among those seven patients, one patient (14.3\%) was with detectable HCV RNA at week 4, as high as and $119 \mathrm{IU} / \mathrm{mL}$, respectively. During the median 20.9 weeks (range, 14.7-77.7 weeks) of follow-up period, all patients achieved virologic response without any relapse or virologic breakthrough during treatment.

Among five patients with previous history of IFN-based therapy, three patients (60\%) achieved virologic response, at week 4 (Table 2). At week 12, four patients (80\%) achieved virologic response. All five patients achieved SVR at 4 weeks after the end of sofosbuvirbased therapy (Table 2). SVR 12 rate was 100\%, even among IFN-experienced cirrhotic patients (Table 3).

Previous history of IFN-based therapy was not associated with virologic response at week 4 (odds ratio [OR], 0.2; 95\% confidence interval $[\mathrm{Cl}], 0.1-2.9 ; P=0.505)$. However, the presence of liver cirrhosis significantly increased the risk of failure for virologic response at week $4(\mathrm{OR}, 11.0 ; 95 \% \mathrm{Cl}, 1.7-71.3 ; P=0.011)$. Five patients with liver cirrhosis at baseline were with Child-Pugh class $A$ and achieved virologic response during the treatment period. 


\section{Virologic responses in genotype 2}

The median duration of sofosbuvir-based therapy for five patients with HCV-genotype 2 was 15.4 weeks (range, 12.9-26.1 weeks). All patients were treated with sofosbuvir + ribavirin for at least 12 weeks. Only one patient (16.7\%) was with detectable HCV RNA at week 4, as high as $44 \mathrm{IU} / \mathrm{mL}$, who had previous history of IFN-based therapy. At week 12, all patients achieved virologic response. SVR 12 rate was 100\% (Table 2 and Table 3).

Previous history of IFN-based therapy $(P=0.8)$ or the presence of liver cirrhosis $(P=0.6)$ was not associated with virologic response at week 4.

\section{Safety}

There was no case of premature discontinuation of sofosbuvir or sofosbuvir/ledipasvir + ribavirin due to adverse events. Only five patients (20\%) with HCV-genotype $1 \mathrm{~b}$ experienced minor adverse events (all grade 1$)$ including fatigue $(n=2)$, mild depressive $\operatorname{mood}(n=1)$, and headache $(n=2)$, which were under control with medication or supportive management.

Initial mean white blood cell (WBC) count was $5.15 \times 10^{3} / \mu \mathrm{L}$ (standard deviation [SD] $0.38 \times 10^{3} / \mu \mathrm{L}$ ). After sofosbuvir-based therapy, the mean WBC changed to $4.18 \times 10^{3} / \mu \mathrm{L}\left(\mathrm{SD} 0.42 \times 10^{3} / \mu \mathrm{L}\right.$ ). However, WBC did not decrease significantly after sofosbuvirbased therapy. While, hemoglobin decreased significantly from $13.8 \mathrm{~g} / \mathrm{dL}$ (SD $2.4 \mathrm{~g} / \mathrm{dL})$ to $12.2 \mathrm{~g} / \mathrm{dL}$ (SD $2.0 \mathrm{~g} / \mathrm{dL})(P=0.044)$. However, no patient needed transfusion due to sofosbuvir-based therapy.

\section{DISCUSSION}

In this retrospective study analyzing the efficacy of sofosbuvirbased therapy for the CHC patients in Korea, a remarkable SVR 12 rate was noted, as high as $100 \%$ in both HCV genotype $1 \mathrm{~b}$ and 2, and in both treatment-naïve and previously-treated patients. For the HCV genotype $1 \mathrm{~b}$ patients with previous history of IFN-based therapy, HCV RNA was slowly suppressed by sofosbuvir-based therapy. However, SVR rate was not different among treatment-naïve patients and patients with previous history of IFN-based therapy. Sofosbuvir-based IFN-free therapy showed high response rates among patients with both HCV genotype $1 \mathrm{~b}$ and 2 with negligible adverse effects. Hemoglobin slightly decreased after sofosbuvir or sofosbuvir/ledipasvir + ribavirin. How- ever, no patient needed transfusion, and there was no premature discontinuation of sofosbuvir-based therapy. The presence of liver cirrhosis significantly increased the risk of failure for virologic response at week 4. However, SVR 12 rate was as high as $100 \%$.

No clinically significant treatment-emergent adverse events were noted in patients receiving sofosbuvir or sofosbuvir/ledipasvir + ribavirin combination. Hematological abnormality except for mild anemia was noted in patients receiving ribavirin. The low incidence of adverse events related with the relatively short duration of treatment as compared to IFN-based therapy might improve treatment adherence and completion.

Among patients with HCV infection and liver cirrhosis in whom pegylated IFN + ribavirin treatment has failed, SVR rates to retreatment with IFN-containing regimens are as low as $14 \%{ }^{16-21}$ In addition, treatment for HCV infection, especially with IFN-based regimens, in patients with liver cirrhosis is associated with increased toxic effects. ${ }^{22,23}$ In this study, we found that sofosbuvirbased therapy shows potent antiviral effect even in CHC patients with liver cirrhosis. However, slightly slow response rate was noted among the patients with cirrhosis which is known as a factor associated with a poor response. Cirrhotic patients with HCV infection have experienced low response rate with interferon-based therapy or protease-inhibitor containing regimen in many studies. ${ }^{16,18,19,24,25}$ The exact mechanism of cirrhosis on response to treatment has not been identified yet. Serum HCV RNA declines in two phases: the rapid first phase and followed by a more gradual second phase of decline. Cirrhotic patients experience slower second phase decline as compared to non-cirrhotic patients. ${ }^{26}$ Therefore, close follow-up and monitoring HCV RNA is needed for cirrhotic CHC patients and sufficient duration of DAAs-combination is warranted to achieve SVR 12 , as high as $100 \% \cdot 18,19,24,27$ In EASL guideline, 8 weeks of duration for sofosbuvir/ledipasvir is also recommended for $\mathrm{CHC}$ genotype 1 patients without cirrhosis. ${ }^{8}$ However, all patients included in this study received sofosbuvir/ledipasvir plus ribavirin for more than 12 weeks, due to lack of Korean experiences. Based on our results, 8 weeks of sofosbuvir/ ledipasvir plus ribavirin might be sufficient to achieve SVR 12 in CHC genotype 1 patients without cirrhosis in Korea. Moreover, efficacy of sofosbuvir/ledipasvir without ribavirin in Korea should be further investigated.

Combinations of DAAs for 12-24 weeks have established the potential of IFN-free regimens for both treatment-naive patients and IFN-experienced patients with HCV genotype $1 \mathrm{~b}$ or 2 infections. ${ }^{28-32}$ IFN-free regimens are becoming the new standard of treatment for CHC patients in Western countries. Official approval 
for DAAs in Asia countries lags behind that in the Western countries. However, several DAAs are becoming available for clinical use in Korea. This study demonstrates real-life management data of initial experiences for sofosbuvir-based therapy which has highly potent antiviral activity against HCV, and has been approved and will be commercially available in a few months in Korea. Our initial experience might provide helpful guidance for clinical use of DAAs, as to the best strategies for $\mathrm{CHC}$ management in Korea.

In conclusion, sofosbuvir-based IFN-free therapy could provide a short, all-oral treatment which is effective in both treatment-naive and previously treated $\mathrm{CHC}$ patients. Further large scale real world studies are warranted when sofosbuvir-based therapy is commercially available in Korea. Importantly, sofosbuvir-based IFN-free therapy might be highly effective and safe in $\mathrm{CHC}$ patients including those who have not responded to standard ofcare IFN-based regimens.

\section{Author contributions}

YJ Kim was the principal investigator and was responsible for the design of the study. Y Cho undertook data assembly, analysis, writing the manuscript, and interpretation. EJ Cho, JH Lee, SJ Yu, and $\mathrm{JH}$ Yoon provided technical and material support. All authors critically reviewed the manuscript and approved the final version for journal submission.

\section{Conflicts of Interest}

The authors have no conflicts to disclose.

\section{REFERENCES}

1. Ghany MG, Strader DB, Thomas DL, Seeff LB; American Association for the Study of Liver D. Diagnosis, management, and treatment of hepatitis C: an update. Hepatology 2009:49:1335-1374.

2. Shiffman ML, Suter $F$, Bacon BR, Nelson D, Harley $H$, Sola $R$, et al. Peginterferon alfa-2a and ribavirin for 16 or 24 weeks in HCV genotype 2 or 3. N Engl J Med 2007;357:124-134.

3. Fried MW, Shiffman ML, Reddy KR, Smith C, Marinos G, Goncales $\mathrm{FL}$, Jr., et al. Peginterferon alfa-2a plus ribavirin for chronic hepatitis C virus infection. N Engl J Med 2002;347:975-982.

4. Sulkowski MS, Cooper C, Hunyady B, Jia J, Ogurtsov P, PeckRadosavljevic $\mathrm{M}$, et al. Management of adverse effects of Peg-IFN and ribavirin therapy for hepatitis C. Nat Rev Gastroenterol Hepatol 2011;8:212-223.
5. Falck-Ytter Y, Kale H, Mullen KD, Sarbah SA, Sorescu L, McCullough AJ. Surprisingly small effect of antiviral treatment in patients with hepatitis C. Ann Intern Med 2002;136:288-292.

6. Lam AM, Murakami E, Espiritu C, Steuer HM, Niu C, Keilman M, et al. PSI-7851, a pronucleotide of beta-D-2'-deoxy-2'-fluoro-2'-Cmethyluridine monophosphate, is a potent and pan-genotype inhibitor of hepatitis C virus replication. Antimicrob Agents Chemother 2010;54:3187-3196.

7. Panel AlHG. Hepatitis C Guidance: AASLD-IDSA recommendations for testing, managing, and treating adults infected with hepatitis $C$ Virus. Hepatology 2015;62:932-954.

8. European Association for Study of L. EASL Recommendations on Treatment of Hepatitis C 2015. J Hepatol 2015;63:199-236.

9. Lawitz EJ, Gruener D, Hill JM, Marbury T, Moorehead L, Mathias A, et al. A phase 1, randomized, placebo-controlled, 3-day, dose-ranging study of GS-5885, an NS5A inhibitor, in patients with genotype 1 hepatitis C. J Hepatol 2012;57:24-31.

10. Gane EJ, Stedman CA, Hyland RH, Ding X, Svarovskaia E, Symonds $W T$, et al. Nucleotide polymerase inhibitor sofosbuvir plus ribavirin for hepatitis C. N Engl J Med 2013;368:34-44.

11. Hagan LM, Sulkowski MS, Schinazi RF. Cost analysis of sofosbuvir/ ribavirin versus sofosbuvir/simeprevir for genotype 1 hepatitis $C$ virus in interferon-ineligible/intolerant individuals. Hepatology 2014;60:37-45

12. European Association for the Study of the Liver. Electronic address eee. EASL Recommendations on Treatment of Hepatitis C 2015. J Hepatol 2015;63:199-236.

13. Kowdley KV, Gordon SC, Reddy KR, Rossaro L, Bernstein DE, Lawitz $\mathrm{E}$, et al. Ledipasvir and sofosbuvir for 8 or 12 weeks for chronic HCV without cirrhosis. N Engl J Med 2014;370:1879-1888.

14. Jacobson IM, Gordon SC, Kowdley KV, Yoshida EM, Rodriguez-Torres M, Sulkowski MS, et al. Sofosbuvir for hepatitis C genotype 2 or 3 in patients without treatment options. N Engl J Med 2013;368:18671877.

15. Castera $L$, Forns $X$, Alberti A. Non-invasive evaluation of liver fibrosis using transient elastography. J Hepatol 2008;48:835-847.

16. Bacon BR, Gordon SC, Lawitz E, Marcellin P, Vierling JM, Zeuzem $\mathrm{S}$, et al. Boceprevir for previously treated chronic HCV genotype 1 infection. N Engl J Med 2011;364:1207-1217.

17. Bourliere M, Khaloun A, Wartelle-Bladou C, Oules V, Portal I, Benali $S$, et al. Future treatment of patients with HCV cirrhosis. Liver Int 2012;32 Suppl 1:113-119.

18. Jacobson IM, McHutchison JG, Dusheiko G, Di Bisceglie AM, Reddy $\mathrm{KR}$, Bzowej NH, et al. Telaprevir for previously untreated chronic hepatitis C virus infection. N Engl J Med 2011;364:2405-2416.

19. Poordad F, McCone J Jr, Bacon BR, Bruno S, Manns MP, Sulkowski MS, et al. Boceprevir for untreated chronic HCV genotype 1 infection. N Engl J Med 2011;364:1195-1206. 
20. Sherman KE, Flamm SL, Afdhal NH, Nelson DR, Sulkowski MS, Everson GT, et al. Response-guided telaprevir combination treatment for hepatitis C virus infection. N Engl J Med 2011;365:1014-1024.

21. Vierling JM, Davis M, Flamm S, Gordon SC, Lawitz E, Yoshida EM, et al. Boceprevir for chronic HCV genotype 1 infection in patients with prior treatment failure to peginterferon/ribavirin, including prior null response. J Hepatol 2014;60:748-756.

22. Colombo M, Fernandez I, Abdurakhmanov D, Ferreira PA, Strasser SI, Urbanek P, et al. Safety and on-treatment efficacy of telaprevir: the early access programme for patients with advanced hepatitis C. Gut 2014;63:1150-1158.

23. Hezode C, Fontaine H, Dorival C, Larrey D, Zoulim F, Canva V, et al. Triple therapy in treatment-experienced patients with HCV-cirrhosis in a multicentre cohort of the French Early Access Programme (ANRS CO20-CUPIC) - NCT01514890. J Hepatol 2013;59:434-441.

24. Ghany MG, Nelson DR, Strader DB, Thomas DL, Seeff LB, American Association for Study of Liver D. An update on treatment of genotype 1 chronic hepatitis C virus infection: 2011 practice guideline by the American Association for the Study of Liver Diseases. Hepatology 2011;54:1433-1444.

25. Afdhal N, Zeuzem S, Kwo P, Chojkier M, Gitlin N, Puoti M, et al. Ledipasvir and sofosbuvir for untreated HCV genotype 1 infection. N Engl J Med 2014;370:1889-1898.

26. Medeiros-Filho JE, de Carvalho Mello IM, Pinho JR, Neumann AU, de Mello Malta F, da Silva LC, et al. Differences in viral kinetics between genotypes 1 and 3 of hepatitis $C$ virus and between cirrhotic and non-cirrhotic patients during antiviral therapy. World J Gastro- enterol 2006;12:7271-7277.

27. Afdhal NH, Dusheiko GM, Giannini EG, Chen PJ, Han KH, Mohsin A, et al. Eltrombopag increases platelet numbers in thrombocytopenic patients with HCV infection and cirrhosis, allowing for effective antiviral therapy. Gastroenterology 2014;146:442-452.e441.

28. Poordad F, Lawitz E, Kowdley KV, Cohen DE, Podsadecki T, Siggelkow $\mathrm{S}$, et al. Exploratory study of oral combination antiviral therapy for hepatitis C. N Engl J Med 2013;368:45-53.

29. Lok AS, Gardiner DF, Lawitz E, Martorell C, Everson GT, Ghalib R, et al. Preliminary study of two antiviral agents for hepatitis $C$ genotype 1. N Engl J Med 2012;366:216-224.

30. Gane EJ, Roberts SK, Stedman CA, Angus PW, Ritchie B, Elston R, et al. Oral combination therapy with a nucleoside polymerase inhibitor (RG7128) and danoprevir for chronic hepatitis C genotype 1 infection (INFORM-1): a randomised, double-blind, placebo-controlled, dose-escalation trial. Lancet 2010;376:1467-1475.

31. Chayama K, Takahashi S, Toyota J, Karino Y, Ikeda K, Ishikawa H, et al. Dual therapy with the nonstructural protein $5 \mathrm{~A}$ inhibitor, daclatasvir, and the nonstructural protein 3 protease inhibitor, asunaprevir, in hepatitis $\mathrm{C}$ virus genotype $1 \mathrm{~b}$-infected null responders. Hepatology 2012;55:742-748.

32. Lawitz E, Poordad F, Kowdley KV, Cohen DE, Podsadecki T, Siggelkow $\mathrm{S}$, et al. A phase 2a trial of 12-week interferon-free therapy with two direct-acting antivirals (ABT-450/r, ABT-072) and ribavirin in IL28B C/C patients with chronic hepatitis C genotype 1. J Hepatol 2013;59:18-23. 